\title{
Lonely and thinking about the past: the role of time perspectives, Big Five traits and perceived social support in loneliness of young adults during COVID-19 social distancing
}

\author{
Iwona Nowakowska (D) \\ Institute of Psychology, The Maria Grzegorzewska University, Warsaw, Poland
}

\section{BACKGROUND}

In the spring of 2020, due to the COVID-19 pandemic, the Polish government introduced a policy of social distancing. Being apart from one's social network had the potential to evoke feelings of loneliness. The aim of the study was to find out how time perspectives might contribute to feeling lonely during the social distancing period, controlling for Big Five personality traits and perceived social support.

\section{PARTICIPANTS AND PROCEDURE}

The study was online, questionnaire-based and cross-sectional $(N=964)$ and was conducted among young adults (aged 18-35) at the end of the third week of social distancing in Poland.

\section{RESULTS}

The results suggested that the Past-Negative time perspective remained significant predictor of loneliness when controlling for Big Five traits and perceived social support. Emotional stability, extroversion and perceived social support were also significant predictors of low loneliness.

\section{CONCLUSIONS}

Negative beliefs about the past may contribute to experiencing greater loneliness when being apart from one's social network.

\section{KEY WORDS}

Big Five; COVID-19; loneliness; time perspective; social support

CORRESPONDING AUthor - Iwona Nowakowska, Institute of Psychology, The Maria Grzegorzewska University,

40 Szczęśliwicka Str., 02-353 Warsaw, Poland, e-mail: insd2@aps.edu.pl

AUthors' CONTRIBUtion - A: Study design - B: Data collection - C: Statistical analysis - D: Data interpretation

E: Manuscript preparation · F: Literature search · G: Funds collection

TO CITE THIS ARTICLE - Nowakowska, I. (2020). Lonely and thinking about the past: the role of time perspectives, Big

Five traits and perceived social support in loneliness of young adults during COVID-19 social distancing. Current

Issues in Personality Psychology, 8(3), 175-184.

RECEIVED 20.04.2020 • REVIEWED 07.05.2020 • ACCEPTED 02.07.2020 • PUBLISHED 03.09.2020 


\section{BACKGROUND}

In the spring of 2020, the coronavirus from the Chinese province Hubei spread worldwide, affecting the whole of Europe. In Poland, 'patient zero' was diagnosed with coronavirus on March $4^{\text {th }}$. On March $12^{\text {th }}$, the first person died from COVID-19 on Polish territory. Since then, a number of restrictions on social contact have been introduced gradually. The goal of these restrictions was 'to flatten the curve' of the infected patients and therefore the death rate, so that medical staff could manage the crisis and be able to help as many patients in need as possible (Hirsch, 2020; Okruszek, Aniszewska-Stańczuk, Piejka, Wiśniewska, \& Żurek, 2020). On March $13^{\text {th }}$ the state of epidemic threat was introduced in Poland, followed by the legal obligation of social distancing on March $24^{\text {th }}-$ a lock-down like measure to limit the number of new infections. This lock-down meant restrictions regarding travel, the inability to meet friends and family, and, for many people, refraining from going to work, and leaving home only in extraordinary cases or in case of urgent, everyday life needs (Hirsch, 2020). Low frequency of contact with family and friends in general, as well as constraints in playing social roles. may contribute to a heightened risk of feeling lonely (Hawkley \& Cacioppo, 2010), and both of these conditions were part of the lock-down during COVID-19 social distancing in Poland (Orzechowska \& Bednarek, 2020).

Loneliness is a complex psychological condition, an unpleasant experience of having a network of social relations that is qualitatively or quantitatively deficient (Perlman \& Peplau, 1981). The characteristic features of loneliness are, for instance, a feeling of emptiness, lack of control, rejection, worthlessness and personal threat, as well as absence (chronic or temporary) of satisfactory social bonds (de JongGierveld, van Tilburg, \& Dykstra, 2006).

According to a novel, worldwide study on the role of age, gender and cultural differences in loneliness of adults (conducted on $N=46,054$ participants; Barreto et al., 2020), younger people, men and people in individualistic cultures report more loneliness than older people, women and people in collectivist cultures, respectively. These results suggest that age, gender and information about the culture of origin of participants (in the case of intercultural studies) need to be included as potential contributors to feelings of loneliness. Moreover, according to this report, compared to other adult age groups, young adults seem to be most prone to feelings of loneliness. Loneliness during COVID-19 social distancing has already been proven to be correlated with mental health symptoms, increased concern about social isolation and risk perception in young adults in Poland (Okruszek et al., 2020). It is worthwhile to find out what factors are associated with loneliness during social isolation so as to understand how it might be relieved and addressed.

Research suggests that among psychological variables, perceived social support, defined as the perceived availability, usefulness and worth of particular sources of support (e.g., family, friends, significant others) (Zimet, Dahlem, Zimet, \& Farley, 1988) might be predictors of loneliness (Lee \& Goldstein, 2016; Salimi \& Bozorgpour, 2012). Furthermore, intrapersonal (dispositional, cognitive) processes may also be associated with loneliness (for a meta-analysis, see, e.g., Buecker, Maes, Denissen, \& Luhmann, 2020). For instance, personality traits such as agreeableness, emotional stability/neuroticism or extroversion may be associated with how a person behaves and what kind of interactions they enter, resulting in either rewarding or unsatisfactory social relations and feelings of belonging or rejection - and loneliness (Larose, Guay, \& Boivin, 2002). Moreover, cognitive biases, such as beliefs about oneself and the surrounding world, may be associated with loneliness (Spithoven, Bijttebier, \& Goossens, 2017). An example of such a bias, yet rarely investigated in loneliness studies, might be the habitual usage of a particular time perspective in assigning experiences to temporal frames (Zimbardo \& Boyd, 1999).

\section{TIME PERSPECTIVES AND LONELINESS}

Time perspective is defined as a process of assigning the flow of experiences - personal and social - to temporal categories. This process enables us to give order, meaning and coherence to life events (Zimbardo \& Boyd, 1999). It might contribute to assessing a present situation by matching it to previous experiences (encoded schematically) through a top-down cognitive process (Clore \& Ortony, 2000). Momentary time perspective is dependent on a wide variety of factors; however, people sometimes tend to concentrate on a particular timeframe when forming appraisals - and that is when a time perspective becomes a habit and might be viewed as an element of personality (Zimbardo \& Boyd, 2008).

Zimbardo and Boyd (1999, 2008) have distinguished five time perspectives: Past-Negative, PastPositive, Present-Hedonistic, Present-Fatalistic, and Future. A Past-Negative time perspective is connected with a discouraged view of the past, which influences the interpretation of the present. A Past-Positive time perspective is connected with nostalgia of the past (Sedikides, Wildschut, Gaertner, Routledge, \& Arndt, 2008). A Present-Hedonistic time perspective means taking advantage of what comes into one's life and of the pleasure from available opportunities. A PresentFatalistic time perspective results in thinking about the present as being impossible to be influenced. A Future time perspective results in thinking about 
future consequences and planning subsequent steps to achieve desired goals (Zimbardo \& Boyd, 1999). Time perspectives contribute importantly to how people perceive, form their expectations, interpret events, make decisions, direct their attention and actions and set new goals (Anagnostopoulos \& Griva, 2012; Zimbardo \& Boyd, 1999). Past time perspectives have been proven to be linked to emotional outcomes (Stolarski, Matthews, Postek, Zimbardo, \& Bitner, 2014; Zhang, Howell, \& Stolarski, 2013), whereas present and future time perspectives have been found to predict behaviors (Chittaro \& Vianello, 2013). Thus, time perspectives, especially past, might be important contributors to emotional states such as loneliness during the COVID-19 lock-down.

Despite the fact that current data on the direct associations between time perspectives and loneliness are scarce, the definitions of particular time perspectives and the empirical evidence about their correlates make them promising variables to be tested in terms of their predictive validity for levels of loneliness. A Past-Negative time perspective enhances discouraged views of the past, creating painful memories (Matthews \& Stolarski, 2015). It might be associated with reporting low life satisfaction, including a low number of satisfactory social relationships (Anagnostopoulos \& Griva, 2012; Zimbardo \& Boyd, 1999), and this might be associated with experiencing loneliness. In contrast, a Past-Positive time perspective might be related to a nostalgic, sentimental view of the past and may be a repository of positive affect. It might also encourage the strengthening of social support, and relational bonds, both known to be associated with lower loneliness (Lee \& Goldstein, 2016), providing a sense of purpose in life and helping a person to cope with existential fears by cultivating rituals and traditions known from the past (Sedikides, Wildschut, \& Baden, 2004). Although this is not direct evidence, such characteristics of the Past-Positive time perspective might be a potential negative correlates of loneliness.

Although, as discussed above, present and future time perspectives are more linked to behaviors than to emotional outcomes, a relatively novel pilot study by Bergman and Segel-Karpas (2018) suggested that the Future time perspective is negatively linked to loneliness. However, this association was confirmed for middle-aged adults and needs further investigation in the age group of young adults.

It is still unknown as to whether time perspectives might remain significant predictors of loneliness when accounting for variables that are especially important to this construct: age, gender, perceived social support, and Big Five personality traits. For well-being (Zhang \& Howell, 2011), mood states and satisfaction with life (Stolarski \& Matthews, 2016), time perspectives were responsible for a substantial portion of variance over and above Big Five traits; therefore it is worth investigating whether a similar pattern can be observed for loneliness. It is also still unknown whether these relationships can be confirmed in the specific context of COVID-19 social distancing. This study aims to answer these questions.

\section{CURRENT STUDY}

The main aim of the current study was to contribute to the understanding of the validity of time perspectives in predicting the level of loneliness of young adults experienced during the COVID-19 social distancing, when controlling for predictors of loneliness available in the literature: age, gender, perceived social support, and personality traits. The subject was novel at the time of planning the study and therefore no previous studies attempted to find out such associations.

Although the empirical data on time perspectives and loneliness to date are scarce, the following hypotheses were conceived based on theoretical assumptions and available empirical studies as discussed above:

H1: Past time perspectives will predict feelings of loneliness during the COVID-19 social distancing in such a way that a Past-Negative time perspective will be associated with greater loneliness, whereas a Past-Positive time perspective will be associated with lower loneliness.

H2: A Future time perspective will predict lower levels of loneliness during the COVID-19 social distancing.

H3: Time perspectives will remain significant predictors of loneliness during COVID-19 home isolation even when accounting for already confirmed predictors of loneliness: age, gender, Big Five personality traits and perceived social support.

\section{PARTICIPANTS AND PROCEDURE}

\section{PARTICIPANTS}

A total of 1293 participants attempted to fill out the questionnaire set; however, 964 matched the inclusion criteria (the inclusion criteria are described below in the Preliminary analyses section). Regarding gender, 193 were male (20.1\%), 763 female (79.1\%), 8 other or no information was provided $(0.8 \%)$. The mean age of the participants was $23.19(S D=3.26)$. In standard (non-epidemic) circumstances, 142 (14.7\%) of the participants were living in the country, 169 $(17.5 \%)$ in a town of fewer than 100,000 inhabitants, $249(25.8 \%)$ in a town of 100,001-499,999 inhabitants and $404(41.9 \%)$ in a town of over 500,000 inhabitants. $259(26.9 \%)$ of the participants spent the home isolation period in the country, $235(24.4 \%)$ in a town of fewer than 100,000 inhabitants, $184(19.1 \%)$ in a town 
of 100,001-499,999 inhabitants, $286(29.7 \%)$ in a town of over 500,000 inhabitants.

None of the participants had been diagnosed with coronavirus/COVID-19. Twenty-two participants (2.3\%) had been quarantined by state entities since the outbreak of the epidemic.

\section{PROCEDURE}

The study was conducted online at the end of the fifth week of the COVID-19 outbreak in Poland and the third week since the social distancing procedures in Poland began. The participants were recruited from Facebook groups dedicated to higher education students as well as from groups for inhabitants of Polish cities. The questionnaires were available to be filled out within 3 days so as to ensure relative stability of the context of the epidemic development. The study was described as "a study of feelings and behaviors during COVID-19" and addressed to people in the 18-35 age bracket. The set consisted of a demographic survey and 4 questionnaires measuring (in order of appearance in the set): loneliness (adapted so as to reflect feelings in the 2 weeks preceding the study), Big Five personality traits, time perspectives and perceived social support. There was a question checking the attention of participants (a request to tick one defined option). The study was anonymous. Prior to filling out questionnaires, all of the participants provided informed consent to take part in the study with no remuneration.

\section{MEASURES}

Loneliness in the 2 weeks preceding the study. Loneliness in the 2 weeks preceding the study was reported with the Polish version of the Revised UCLA Loneliness Scale (Russell, 1996; Polish version: Kwiatkowska, Rogoza, \& Kwiatkowska, 2017) with an alteration in the instruction which stated that the participant should think about the two weeks preceding the survey when answering the questions. In this altered instruction there was no direct reference to COVID-19 social distancing. The scale consists of 20 items (e.g., I can find companionship when I want it; I feel isolated from others) with answers ranging from 1 (never) to 4 (often). The scale has 3 subscales; however, the general score was of interest for the purpose of the current study.

Big Five personality traits. Personality traits were measured using the IPIP-BFM-20, which is a short, 20-item operationalization of the Big Five traits (Mini-IPIP; Donnellan, Oswald, Baird, \& Lucas, 2006; Polish version: IPIP-BFM-20; Topolewska, Skimina, Strus, Cieciuch, \& Rowiński, 2017). The questionnaire aims to find out the level of the following traits among the participants: agreeableness (4 items, e.g., I sympathize with others' feelings), conscientiousness (4 items, e.g., I get chores done right away), emotional stability (4 items, e.g., I am relaxed most of the time), extroversion (4 items, e.g., I talk to a lot of different people at parties), and intellect (4 items, e.g., I have difficulty understanding abstract ideas).

Time perspectives. Time perspectives were assessed using the Polish Short Zimbardo Time Perspective Inventory (PS-ZTPI; Przepiorka, Sobol-Kwapinska, \& Jankowski, 2016). This 20 -item scale aims to find out the levels of four time perspectives of a participant: Past-Negative (5 items, e.g., I think about the bad things that have happened to me in the past), PastPositive (5 items, e.g., Happy memories of good times spring readily to mind), Present-Hedonistic (5 items, e.g., Taking risks keeps my life from becoming boring) and Future (5 items, e.g., Meeting tomorrow's deadline and doing other necessary work comes before tonight's play).

Perceived social support. Perceived social support was reported with the Multidimensional Perceived Social Support Scale (MPSSS; Zimet et al., 1988; Zimet, Powell, Farley, Werkman, \& Berkoff, 1990; the Polish version by Buszman \& Przybyła-Basista, 2017). This 12-item scale aims to find out how a person perceives support from three sources: one's family (4 items, e.g., I get the emotional help and support I need from my family), friends (4 items, e.g., I can count on my friends when things go wrong) and significant other (4 items, e.g., There is a special person in my life who cares about my feelings).

\section{POWER ANALYSIS}

Prior to conducting the study, a power analysis was conducted in $\mathrm{G}^{*}$ Power 3.1 (Faul, Erdfelder, Buchner, \& Lang, 2009). The minimal sample size was determined for a linear multiple regression based model with initial settings: effect size .05, $\alpha$ error probability .05 , power .95; stating that at least 262 participants should take part in the study to achieve the desired parameters.

\section{STATISTICAL ANALYSES}

All analyses for this study were performed using IBM SPSS 25.0.0.2 for Windows.

\section{PRELIMINARY ANALYSES}

As mentioned above, at first, participants who did not match the inclusion criteria (filling out the set until its end, matching the age criterion of being between 18 and 35, a correct answer to the attention check) 
were filtered out from the database. Then, results in the subscales of the questionnaires, as well as general scores for each of them, were calculated using means of results in items reflecting each subscale or scale (preceded with reverse coding of items where applicable, according to the author instructions). Given that the study was done online, filling out all items in each questionnaire was obligatory to finish the study; therefore there were no missing data.

Data about gender were recoded so as to create a dichotomous variable (with " 0 " for females, " 1 " for males and missing data for other responses). Then, the scores for the subscales (for IPIP-BFM-20 and PS-ZTPI) as well as general scores (for R-UCLA and MPSSS) for the questionnaires were computed so as to enable further planned analyses. The general results in the subscales and general scale scores (where applicable) were obtained by calculating means of the answers to the relevant items.

\section{ANALYTIC STRATEGY}

To investigate the hypotheses stated above, the correlations between the subscales of each of the questionnaires and the general scores were computed in the first step. In the following step, the hypotheses were tested using hierarchical regression analysis.

\section{RESULTS}

To illustrate the associations between the variables examined in the study, a correlation analysis was conducted, the results of which are presented in Table 1.

As predicted, Past-Positive and Past-Negative correlated with loneliness during the COVID-19 social distancing period. The Past-Positive time perspective correlated negatively with loneliness, whereas the Past-Negative time perspective correlated positively with this variable. The Future time perspective also appeared to correlate negatively with loneliness during the COVID-19 social distancing period; however, the correlation was lower than for the Past time perspeTo test the predictive validity of time perspectives on the loneliness perceived during the COVID-19 social distancing period, a series of hierarchical regression analyses was performed. The subsequent steps of the analyses conformed to the hypotheses stated above. The results of these analyses are presented in Table 2.

In the first stage, the potential confounder variables (age and gender) were introduced to the model, predicting $1.2 \%$ of total variance in perceived loneliness. Age was a significant contributor to the variance in loneliness, so that the younger the participants, the higher the level of loneliness. Next, time perspectives were introduced to the model, predict- ing a further $28.5 \%$ of the total variance. Only the effects of the Past-Negative and Past-Positive time perspectives were significant, with higher levels of the Past-Positive time perspective predicting lower loneliness, and higher levels of the Past-Negative time perspective being predictive of higher levels of perceived loneliness. In the third step, Big Five personality traits were introduced to the model, predicting a further $9.7 \%$ of the variance in perceived loneliness. The effects of Past time perspectives remained statistically significant, and among Big Five traits, agreeableness, emotional stability and extroversion appeared to be significant predictors of perceived loneliness. Lastly, perceived social support from one's family, friends and significant other was introduced to the model, predicting a further $14.2 \%$ of the variance. All of the forms of perceived social support appeared to be significant predictors of loneliness during the COVID-19 social distancing. After introducing social support forms as potential predictors to the model, only the Past-Negative time perspective, emotional stability and extroversion remained significant predictors of the total variance of the dependent variable. The full model accounted for $53.6 \%$ of the variance in the loneliness experienced during the COVID-19 social distancing.

\section{CONCLUSIONS}

The main aim of this study was to explore whether the loneliness of young adults during the COVID-19 social distancing might be affected by time perspectives and whether they remain significant predictors of loneliness when accounting for Big Five traits and social support from various sources.

The analyses showed that a Past-Negative time perspective is a predictor of loneliness perceived during the COVID-19 social distancing period, even when accounting for Big Five personality traits and perceived social support from one's family, friends and significant other. A Past-Negative time perspective evokes a discouraging, disheartened view of the past, which may contribute to how a person reacts in the present (Anagnostopoulos \& Griva, 2012). However, another way of thinking about the past, a Past-Positive time perspective, did not remain significant when introducing perceived social support to the model. The results suggest that perceptions of the past are important for dealing with the social distancing situation. It might be hypothesized that targeting such negative temporal bias has a potential to be helpful in overcoming the difficulties of isolation during COVID-19.

The Big Five traits emotional stability and extroversion also significantly predicted feelings of loneliness during the COVID-19 social distancing period. This confirmed previous results regarding the role of 


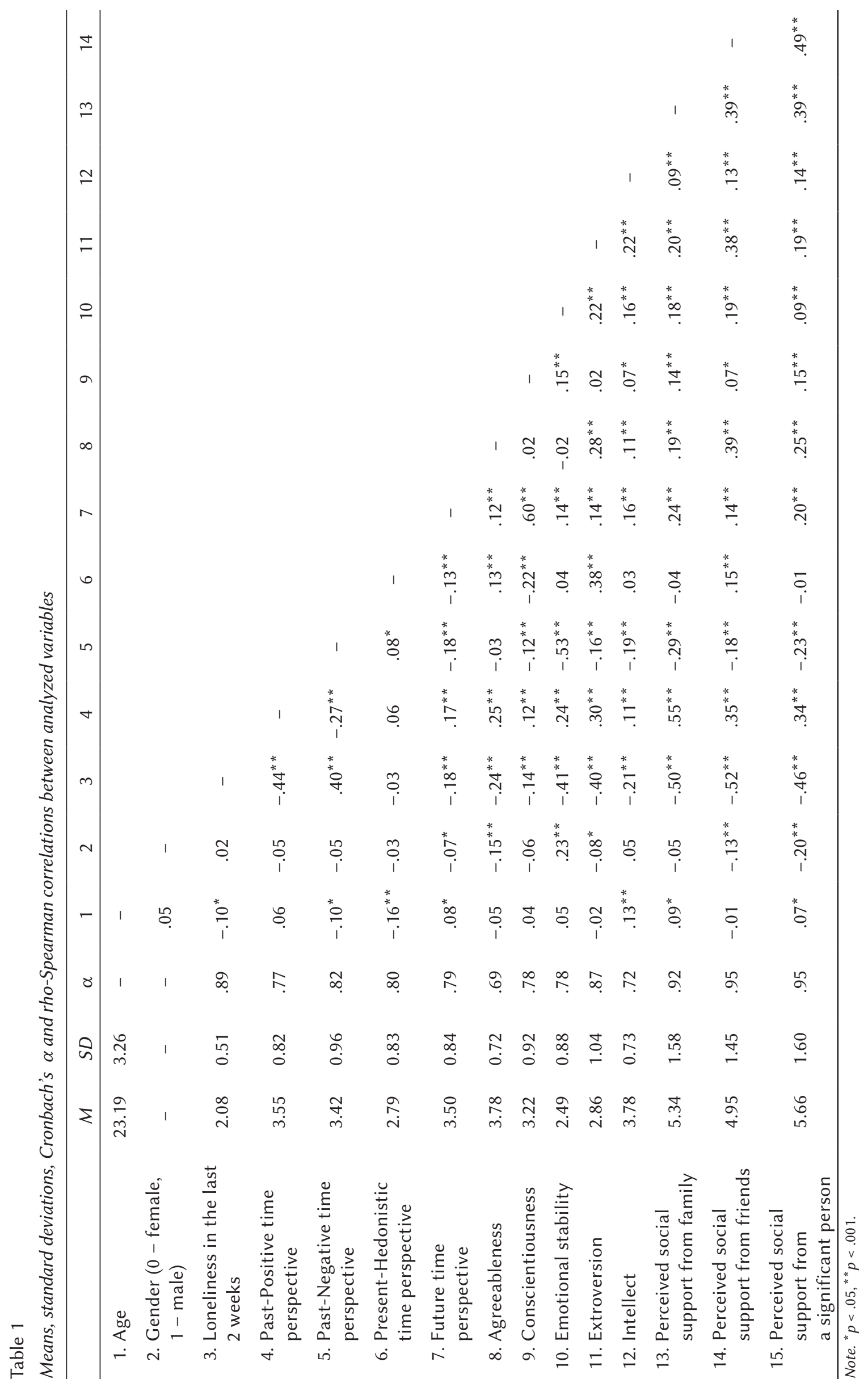


Table 2

Linear multiple regression analysis predicting the level of perceived loneliness during COVID-19 social distancing

\begin{tabular}{|c|c|c|c|c|c|c|c|c|}
\hline Model & Predictors & B & $S E \mathrm{~B}$ & $\beta$ & $p$ & $F$ & $R^{2} / \Delta R^{2}$ & VIF \\
\hline \multirow[t]{2}{*}{ I } & Age & -.02 & .01 & -.11 & $<.001$ & 5.87 & $R^{2}=.01$ & 1.00 \\
\hline & Gender & .04 & .04 & .03 & .360 & & & 1.00 \\
\hline \multirow[t]{6}{*}{ II } & Age & -.01 & .00 & -.06 & .042 & 66.71 & $\Delta R^{2}=.29$ & 1.04 \\
\hline & Gender & .03 & .04 & .02 & .459 & & & 1.02 \\
\hline & Past-Positive time perspective & -.23 & .02 & -.36 & $<.001$ & & & 1.12 \\
\hline & Past-Negative time perspective & .15 & .02 & .29 & $<.001$ & & & 1.12 \\
\hline & Present-Hedonistic time perspective & -.03 & .02 & -.05 & .101 & & & 1.05 \\
\hline & Future time perspective & -.03 & .02 & -.05 & .055 & & & 1.08 \\
\hline \multirow[t]{11}{*}{ III } & Age & -.01 & .00 & -.06 & .033 & 55.75 & $\Delta R^{2}=.10$ & 1.06 \\
\hline & Gender & .05 & .03 & .04 & .137 & & & 1.12 \\
\hline & Past-Positive time perspective & -.16 & .02 & -.26 & $<.001$ & & & 1.25 \\
\hline & Past-Negative time perspective & .09 & .02 & .16 & $<.001$ & & & 1.52 \\
\hline & Present-Hedonistic time perspective & .04 & .02 & .07 & .015 & & & 1.30 \\
\hline & Future time perspective & .01 & .02 & .02 & .520 & & & 1.74 \\
\hline & Agreeableness & -.08 & .02 & -.12 & $<.001$ & & & 1.16 \\
\hline & Conscientiousness & -.02 & .02 & -.03 & .336 & & & 1.71 \\
\hline & Emotional stability & -.12 & .02 & -.21 & $<.001$ & & & 1.61 \\
\hline & Extroversion & -.11 & .02 & -.23 & $<.001$ & & & 1.45 \\
\hline & Intellect & -.03 & .02 & -.04 & .114 & & & 1.13 \\
\hline \multirow[t]{14}{*}{ IV } & Age & -.01 & .00 & -.04 & .060 & 77.77 & $\Delta R^{2}=.14$ & 1.06 \\
\hline & Gender & -.02 & .03 & -.02 & .541 & & & 1.18 \\
\hline & Past-Positive time perspective & -.04 & .02 & -.06 & .026 & & & 1.66 \\
\hline & Past-Negative time perspective & .05 & .02 & .10 & $<.001$ & & & 1.57 \\
\hline & Present-Hedonistic time perspective & .04 & .02 & .06 & .013 & & & 1.31 \\
\hline & Future time perspective & .03 & .02 & .05 & .077 & & & 1.76 \\
\hline & Agreeableness & -.01 & .02 & -.02 & .508 & & & 1.28 \\
\hline & Conscientiousness & -.01 & .02 & -.02 & .547 & & & 1.72 \\
\hline & Emotional stability & -.11 & .02 & -.19 & $<.001$ & & & 1.64 \\
\hline & Extroversion & -.08 & .01 & -.16 & $<.001$ & & & 1.52 \\
\hline & Intellect & -.03 & .02 & -.04 & -.102 & & & 1.14 \\
\hline & Perceived social support from family & -.08 & .01 & -.23 & $<.001$ & & & 1.61 \\
\hline & $\begin{array}{l}\text { Perceived social support from } \\
\text { friends }\end{array}$ & -.09 & .01 & -.25 & $<.001$ & & & 1.67 \\
\hline & $\begin{array}{l}\text { Perceived social support from } \\
\text { significant other }\end{array}$ & -.05 & .01 & -.16 & $<.001$ & & & 1.49 \\
\hline
\end{tabular}


Big Five traits in experiencing loneliness (Buecker et al., 2020). Emotional stability is a personality trait responsible for responding to stressors and to adverse events in life. Although personality traits are relatively stable, after adverse life events, individuals often struggle to reinstate emotional stability (LopezVazquez \& Marvan, 2003). It suggests that addressing emotional well-being and expression (connected with extroversion) during critical events as they happen might be beneficial to overcoming the feeling of loneliness.

Furthermore, the study confirmed that perceived social support is a significant negative correlate of loneliness, which is consistent with previous studies (Lee \& Goldstein, 2016; Salimi \& Bozorgpour, 2012; Wang, Mann, Lloyd-Evans, Ma, \& Johnson, 2018). All forms of support investigated, namely that received from one's family, friends and significant other, were associated with lower levels of loneliness during social distancing. By definition, loneliness is a deficiency in social contacts and the social network (Perlman \& Peplau, 1981); however, even when accounting for the important factor of how a person perceives the quality of social support received from this network, a Past-Negative time perspective, emotional stability and extroversion remained significant predictors of loneliness. It suggests that not only interpersonal processes, but also personal characteristics are important to survive the time when a social network is unavailable (such as a social distancing period). This finding is in line with studies such as the one by Larose and colleagues (2002).

The study has numerous strengths, such as the fact that the available data on feelings during the COVID-19 crisis are scarce. The study was conducted on a large sample of young Polish adults. The participants were recruited online from various student Facebook groups across Poland, attempting to reduce the bias of arbitrarily recruiting participants from only selected universities or regions of Poland.

The study has a number of limitations. The model accounted for $53.6 \%$ of the variance in loneliness experienced during the COVID-19 social distancing, which suggests that other relevant variables ought to be taken into consideration in further studies to enhance the understanding of the phenomenon. Such variables might be, for instance, information about the frequency of meeting other people during the period of social isolation, as well as the number of household inhabitants (Iecovich, Jacobs, \& Stessman, 2011). Another relevant variable might be related to the situation at work (characteristics of the forms of work: remote or on-site during social isolation and whether employment was maintained or not). Work situation was found to contribute to anxiety and depression during COVID-19 social isolation in Poland (Gambin et al., 2020). Work is also an important source of social contact and social support (Chiaburu,
Van Dam, \& Hutchins, 2010; Kossek, Pichler, Bodner, \& Hammer, 2011).

Moreover, the study was cross-sectional and, by design, focused on one age group (18-35). Remote participant selection was the only possible option, and despite the abovementioned strengths of such a recruitment measure, the possibility of involving participants who were not studying (e.g., people who work or had finished their education) was limited. Moreover, little is known from this study about how people cope with the period of social distancing and what compensation strategies they employ to survive the time of being apart from their social network. Future studies should address these limitations, given that the subject is worth continuing, especially in the subsequent stages of the epidemic.

\section{RefERENCES}

Anagnostopoulos, F., \& Griva, F. (2012). Exploring time perspective in Greek young adults: Validation of the Zimbardo Time Perspective Inventory and relationships with mental health indicators. Social Indicators Research, 106, 41-59. https://doi. org/10.1007/s11205-011-9792-y

Barreto, M., Victor, C., Hammond, C., Eccles, A., Richins, M. T., \& Qualter, P. (2020). Loneliness around the world: Age, gender, and cultural differences in loneliness. Personality and Individual Differences (in press). https://doi.org/10.1016/j.paid.2020.110066

Bergman, Y. S., \& Segel-Karpas, D. (2018). Future time perspective, loneliness, and depressive symptoms among middle-aged adults: A mediation model. Journal of Affective Disorders, 241, 173-175. https://doi.org/10.1016/j.jad.2018.08.019

Buecker, S., Maes, M., Denissen, J. J., \& Luhmann, M. (2020). Loneliness and the Big Five personality traits: A meta-analysis. European Journal of Personality, 34, 8-28. https://doi.org/10.1002/per.2229

Buszman, K., \& Przybyła-Basista, H. (2017). Polska adaptacja Wielowymiarowej Skali Spostrzeganego Wsparcia Społecznego [The Polish adaptation of the Multidimensional Scale of Perceived Social Support]. Polskie Forum Psychologiczne, 22, 581599. https://doi.org/10.14656/PFP20170404

Chiaburu, D. S., Van Dam, K., \& Hutchins, H. M. (2010). Social support in the workplace and training transfer: A longitudinal analysis. International Journal of Selection and Assessment, 18, 187-200. https://doi.org/10.1111/j.1468-2389.2010.00500.x

Chittaro, L., \& Vianello, A. (2013). Time perspective as a predictor of problematic Internet use: A study of Facebook users. Personality and Individual Differences, 55, 989-993. https://doi.org/10.1016/j.paid. 2013.08.007

Clore, G. L., \& Ortony, A. (2000). Cognition in emotion: Always, sometimes, or never? In R. D. Lane 
\& L. Nadel (Eds.), Cognitive neuroscience of emotion (pp. 24-61). New York: Oxford University Press.

de Jong-Gierveld, J., van Tilburg, T. G., \& Dykstra, P. A. (2006). Loneliness and social isolation. In D. Perlman, \& A. Vangelisti (Eds.), The Cambridge handbook of personal relationships (pp. 485-500). Cambridge: Cambridge University Press.

Donnellan, M. B., Oswald, F. L., Baird, B. M., \& Lucas, R. E. (2006). The mini-IPIP scales: tiny-yeteffective measures of the Big Five factors of personality. Psychological Assessment, 18, 192-203. https://doi.org/10.1037/1040-3590.18.2.192

Faul, F., Erdfelder, E., Buchner, A., \& Lang, A. G. (2009). Statistical power analyses using $G^{*}$ Power 3.1: Tests for correlation and regression analyses. Behavior Research Methods, 41, 1149-1160. https://doi. org/10.3758/BRM.41.4.114

Gambin, M., Sękowski, M., Woźniak-Prus, M., Wnuk, A., Oleksy, T., Cudo, A., ... \& Maison, D. (2020). Generalized anxiety and depressive symptoms in various age groups during the COVID-19 lockdown. Specific predictors and differences in symptoms severity [Preprint]. Retrieved from https://psyarxiv.com/42m87/ (June 29, 2020).

Hawkley, L. C., \& Cacioppo, J. T. (2010). Loneliness matters: A theoretical and empirical review of consequences and mechanisms. Annals of Behavioral Medicine, 40, 218-227. https://doi.org/10.1007/ s12160-010-9210-8

Hirsch, C. (2020, March 31). Europe's coronavirus lockdown measures compared. Retrieved from https:// www.politico.eu/article/europes-coronavirus-lockdown-measures-compared/ (April 16, 2020).

lecovich, E., Jacobs, J. M., \& Stessman, J. (2011). Loneliness, social networks, and mortality: 18 years of follow-up. The International Journal of Aging and Human Development, 72, 243-263. https://doi. org/10.2190/AG.72.3.e

Kossek, E. E., Pichler, S., Bodner, T., \& Hammer, L. B. (2011). Workplace social support and work-family conflict: A meta-analysis clarifying the influence of general and work-family-specific supervisor and organizational support. Personnel Psychology, 64(2), 289-313. https://doi.org/10.1111/j.17446570.2011.01211.x

Kwiatkowska, M. M., Rogoza, R., \& Kwiatkowska, K. (2017). Analysis of the psychometric properties of the Revised UCLA Loneliness Scale in the Polish adolescent sample. Current Issues in Personality Psychology, 5, 1-7. https://doi.org/10.5114/ cipp.2017.69681

Larose, S., Guay, F., \& Boivin, M. (2002). Attachment, social support, and loneliness in young adulthood: A test of two models. Personality and Social Psychology Bulletin, 28, 684-693. https://doi. org/10.1177/0146167202288012

Lee, C. Y. S., \& Goldstein, S. E. (2016). Loneliness, stress, and social support in young adulthood:
Does the source of support matter? Journal of Youth and Adolescence, 45, 568-580. https://doi. org/10.1007/s10964-015-0395-9

Lopez-Vazquez, E., \& Marvan, M. L. (2003). Risk perception, stress and coping strategies in two catastrophe risk situations. Social Behavior and Personality: An International Journal, 31, 61-70. https:// doi.org/10.2224/sbp.2003.31.1.61

Matthews, G., \& Stolarski, M. (2015). Emotional processes in development and dynamics of individual time perspective. In M. Stolarski, N. Fieulaine, \& W. van Beek (Eds.), Time perspective theory; review, research and application (pp. 269-286). Cham: Springer. https://doi.org/10.1007/978-3-319-073682_18

Okruszek, Ł., Aniszewska-Stańczuk, A., Piejka, A., Wiśniewska, M., \& Żurek, K. (2020). Safe but lonely? Loneliness, mental health symptoms and COVID-19 [Preprint]. Retrieved from osf.io/9njps, https://doi. org/10.31234/osf.io/9njps (April 16, 2020).

Orzechowska, M., \& Bednarek, A. K. (2020). Forecasting COVID-19 pandemic in Poland according to government regulations and people behavior [Preprint]. Retrieved from https://www.medrxiv.org/ content/10.1101/2020.05.26.20112458v1, https://doi. org/10.1101/2020.05.26.20112458 (June 19, 2020).

Perlman, D., \& Peplau, L. A. (1981). Toward a Social Psychology of Loneliness. In R. Gilmour \& S. Duck (Eds.), Personal Relationships: 3. Relationships in Disorder (pp. 31-56). London: Academic Press.

Przepiorka, A., Sobol-Kwapinska, M., \& Jankowski, T. (2016). A Polish short version of the Zimbardo Time Perspective Inventory. Personality and Individual Differences, 101, 78-89. https://doi.org/10.1016/ j.paid.2016.05.047

Russell, D. W. (1996). UCLA Loneliness Scale (Version 3): Reliability, validity, and factor structure. Journal of Personality Assessment, 66, 20-40. https:// doi.org/10.1207/s15327752jpa6601_2

Salimi, A., \& Bozorgpour, F. (2012). Perceived social support and social-emotional loneliness. Procedia-Social and Behavioral Sciences, 69, 2009-2013. https://doi.org/10.1016/j.sbspro.2012.12.158

Sedikides, C., Wildschut, T., Gaertner, L., Routledge, C., \& Arndt, J. (2008). Nostalgia as enabler of self continuity. In F. Sani (Ed.), Self continuity: Individual and collective perspectives (pp. 227-239). London: Psychology Press.

Sedikides, C., Wildschut, T., \& Baden, D. (2004). Nostalgia: Conceptual issues and existential functions. In J. Greenberg, S. L. Koole, \& T. Pyszczynski (Eds.), Handbook of experimental existential psychology (pp. 200-214). New York: Guilford Press

Spithoven, A. W., Bijttebier, P., \& Goossens, L. (2017). It is all in their mind: A review on information processing bias in lonely individuals. Clinical Psychology Review, 58, 97-114. https://doi.org/10.1016/ j.cpr.2017.10.003 
Stolarski, M., \& Matthews, G. (2016). Time perspectives predict mood states and satisfaction with life over and above personality. Current Psychology, 35, 516-526. https://doi.org/10.1007/s12144-016-9515-2 Stolarski, M., Matthews, G., Postek, S., Zimbardo, P. G., \& Bitner, J. (2014). How we feel is a matter of time: Relationships between time perspectives and mood. Journal of Happiness Studies, 15, 809827. https://doi.org/10.1007/s10902-013-9450-y

Topolewska, E., Skimina, E., Strus, W., Cieciuch, J., \& Rowiński, T. (2014). The short IPIP-BFM-20 questionnaire for measuring the Big Five. Roczniki Psychologiczne, 17, 385-402.

Wang, J., Mann, F., Lloyd-Evans, B., Ma, R., \& Johnson, S. (2018). Associations between loneliness and perceived social support and outcomes of mental health problems: a systematic review. BMC Psychiatry, 18, 156. https://doi.org/10.1186/s12888-0181736-5

Zhang, J. W., \& Howell, R. T. (2011). Do time perspectives predict unique variance in life satisfaction beyond personality traits? Personality and Individual Differences, 50, 1261-1266. https://doi. org/10.1016/j.paid.2011.02.021

Zhang, J. W., Howell, R. T., \& Stolarski, M. (2013). Comparing three methods to measure a balanced time perspective: The relationship between balanced time perspective and subjective well-being. Journal of Happiness Studies, 14, 169-184. https:// doi.org/10.1007/s10902-012-9322-x

Zimbardo, P. G., \& Boyd, J. N. (2008). The time paradox. New York: Free Press.

Zimbardo, P. G., \& Boyd, J. N. (1999). Putting time in perspective: a valid, reliable individual-differences metric. Journal of Personality and Social Psychology, 77, 1271-1288. https://doi.org/10.1037/00223514.77.6.1271

Zimet, G. D., Dahlem, N. W., Zimet, S. G., \& Farley, G. K. (1988). The multidimensional scale of perceived social support. Journal of Personality Assessment, 52, 30-41.

Zimet, G. D., Powell, S. S., Farley, G. K., Werkman, S., \& Berkoff, K. A. (1990). Psychometric characteristics of the multidimensional scale of perceived social support. Journal of Personality Assessment, 55, 610-617. 